\title{
Produtividade da abobrinha 'Caserta' em função do nitrogênio e gel hidrorretentor
}

\section{Zucchini 'Caserta' productivity as a function of nitrogen and gel hidroretentor}

\author{
Leandro Oliveira AZAMBUJA ${ }^{1,2}$; Cleiton Gredson Sabin BENETT ${ }^{3}$; Katiane Santiago Silva BENETT ${ }^{4}$; \\ Edilson COSTA \\ ${ }^{1}$ Trabalho de monografia. Parte apresentada na forma de pôster no II Simpósio Mineiro de Ciência do Solo, 2013, \\ Viçosa-MG. \\ ${ }^{2}$ Agrônomo da Universidade Estadual de Mato Grosso do Sul (UEMS), Unidade Universitária de Aquidauana, e-mail: \\ leandroazambuja1@hotmail.com \\ ${ }^{3}$ Doutor do Departamento de Engenharia Agrícola do Instituto Federal Goiano (IF Goiano), Campus de Urutaí, Rodovia \\ Geraldo Silva Nascimento, km 2,5, CEP: 75790-000, Urutaí-GO, Brasil, e-mail: cleiton.benett@ifgoiano.edu.br \\ ${ }^{4}$ Doutora do Departamento de Agronomia da Universidade Estadual de Goiás (UEG), Unidade Universitária de Ipameri, \\ e-mail: kasantiago@ig.com.br \\ 5 Doutor do Departamento de Agronomia da Universidade Estadual de Mato Grosso do Sul (UEMS), Unidade \\ Universitária de Cassilândia, e-mail: mestrine@uems.br
}

Recebido em: 15-10-2014; Aceito em: 20-05-2015

\begin{abstract}
Resumo
A cultura da abobrinha tem grande importância na economia olerícola, devido a sua produtividade elevada, grande aceitação pelos consumidores e rápido retorno financeiro. O objetivo deste trabalho foi avaliar a aplicação de gel hidrorretentor e doses de nitrogênio $(\mathrm{N})$ sobre os componentes de produção e de produtividade da abobrinha cultivar Caserta. O experimento foi desenvolvido no período de abril a julho, no município de Aquidauana-MS. O delineamento experimental utilizado foi o de blocos casualizados, em esquema fatorial $2 \times 5$, sendo os tratamentos constituídos pela utilização do gel hidrorretentor (com e sem aplicação) e cinco doses de $\mathrm{N}\left(0 ; 50 ; 100 ; 150\right.$ e $\left.200 \mathrm{~kg} \mathrm{ha}^{-1}\right)$, com quatro repetições. A semeadura da abobrinha 'Caserta' foi realizada manual e diretamente nas covas. As doses de $\mathrm{N}$ foram aplicadas em dose única, ao redor de cada cova, aos 20 dias após a emergência. Foram avaliados os teores de $\mathrm{N}$ foliar, a altura de planta, o diâmetro de caule, o comprimento de frutos, o diâmetro apical, médio e basal do fruto, o número e a produtividade comercial de frutos. A aplicação do gel hidrorretentor não influencia na produção da abobrinha cultivar Caserta. As doses de nitrogênio incrementam linearmente os componentes de produção, tanto para o número de frutos quanto para a produtividade.
\end{abstract}

Palavras-chave adicionais: Cucurbita pepo; polímero; ureia.

\begin{abstract}
The culture of zucchini is very important vegetable crop in the economy, due to its high productivity, great acceptance by consumers and quick financial return. The objective of this study was to evaluate the application of hidroretentor gel and nitrogen $(\mathrm{N})$ on the components of production and productivity of zucchini grow Caserta. The experiment was conducted in the period from April to July in the city of Aquidauana-MS. The experimental design was using a randomized complete block in a factorial $2 \times 5$, with the treatments constituted by the use of hidroretentor gel (with and without application) and five doses of $N(0.50 .100 .150$ and $200 \mathrm{~kg} \mathrm{ha}^{-1}$ ) with four replications. Sowing of zucchini 'Caserta' was performed manually and directly into the pits. The $\mathrm{N}$ rates were applied in a single dose, around each hole, at 20 days after emergence. We evaluated the leaf $\mathrm{N}$ content, plant height, stem diameter, fruit length, diameter apical, medium, basal fruit number, and commercial fruit yield. The application of hidroretentor gel does not influence the production of zucchini grow Caserta. Nitrogen rates linearly increment the production of components for both the number of fruits and for productivity.
\end{abstract}

Additional keywords: Cucurbita pepo; polymer; urea.

\section{Introdução}

A cultura de abobrinha tem-se destacado entre as olerícolas pelo grande potencial para comercialização, pois além de representar opção produtiva o ano todo para os produtores, ainda possui boa aceitação para o mercado consumidor. A cultivar Caserta (Cucurbita pepo) é de origem americana e é a preferida pelos consumidores e olericultores, além de ser uma das mais produtivas (Klosowski et al., 1999).

No Brasil, a abobrinha está presente entre 
as dez hortaliças de maior valor econômico, com importância econômica elevada, principalmente no Centro e no Sul do País (Carpes et al., 2008). As informações sobre produção e área de plantio são escassas, sendo que a produção brasileira em 2006 foi de 384.916 toneladas e área colhida de 88.203 ha $^{-1}$ (IBGE, 2010).

A abobrinha italiana é uma cucurbitácea de hábito de crescimento ereto, apesar de seu caule herbáceo. A cultivar Caserta é de origem americana é a preferida pelos consumidores e olericultores, além de ser uma das mais produtivas (Klosowski et al., 1999).

Esta cultivar apresenta bom desenvolvimento e produtividade entre 18 a $35^{\circ} \mathrm{C}$. Além disso, esta cultivar desenvolve-se no outono e na primavera, e também durante os invernos amenos das localidades quentes (Filgueira, 2012). Em relação ao solo, a cultura da abobrinha adapta-se facilmente a qualquer tipo; no entanto desenvolve-se melhor em solos arenoargilosos, com pH de 6 a 6,5, firmes e com boa drenagem (Amaro et al., 2007).

O nitrogênio $(\mathrm{N})$ é um dos nutrientes requeridos em maior quantidade pelas culturas para obtenção de altas produtividades. Na planta, possui função estrutural, sendo constituinte de aminoácidos, proteínas, bases nitrogenadas, muitas enzimas e materiais de transferência de energia, como a clorofila, ADP e ATP, tendo também um papel nos processos de absorção iônica, fotossíntese, respiração, multiplicação e diferenciação celular (Malavolta et al., 1997). A dose adequada de $\mathrm{N}$ é variável de acordo com vários fatores, entre os quais se encontram a produtividade almejada, cultivar, técnicas de manejo, fonte e condições edafoclimáticas (Pôrto et al., 2012).

O uso excessivo de fertilizantes, principalmente de $\mathrm{N}$, pode acarretar lixiviação de $\mathrm{N}$ para águas subterrâneas, causando poluição ambiental. Bastos et al. (2008) destacaram que pesquisas regionais visando a determinar as doses econômicas de $\mathrm{N}$ são de grande importância para que o agricultor possa racionalizar o uso de fertilizantes nitrogenados, diminuir os custos de produção e aumentar a rentabilidade da cultura da abobrinha.

A utilização do gel hidrorretentor ou hidrogel (polímero) na agricultura é recomendada tanto para culturas de sequeiro quanto para irrigadas, pois possui importante capacidade de armazenar e disponibilizar água para as plantas (Azevedo et al., 2002), sendo utilizado, principalmente, nas áreas de silvicultura, fruticultura e na composição de substratos para a produção de mudas. Este polímero pode ser utilizado como substância de estímulo para o crescimento de árvores em estufas, em reflorestamento de áreas degradadas, assim como para minimizar os possíveis efeitos de veranicos na fase de implantação da cultura (Oliveira et al., 2004; Vale et al., 2006). Além disso, o gel hidrorretentor apresenta vantagens como aumento na retenção de água no solo; reduz a lixiviação dos nutrientes; melhora a capacidade de troca catiônica e aumenta a disponibilização de água para as plantas (Vale et al., 2006).

Em culturas olerícolas, são poucos os trabalhos com o uso de hidrogel. Marques \& Bastos (2010) verificaram que a adição de hidrogel no substrato, para produção de mudas de pimentão, foi benéfica. Demartelaere et al. (2009), utilizando 0 gel hidrorretentor em meloeiro, associado a lâminas de irrigação, verificaram maior número e produtividade de frutos por metro linear. Em coentro, mesmo submetido a manejo de irrigação que promoveu déficit hídrico, a utilização do polímero hidrorretentor mostrou resultados satisfatórios (Albuquerque Filho et al. 2009).

Desta forma, tendo em vista o mercado da cultura da abobrinha e a adição desta hortaliça na dieta alimentar, bem como para outras finalidades, estes estudos tornam-se de suma importância para o sucesso do cultivo, permitindo que os produtores obtenham maior lucratividade e qualidade na produção. Adiciona-se a isso os poucos trabalhos relacionados à aplicação de gel hidrorretentor associado a fertilizantes, principalmente para as culturas olerícolas, sendo que a utilização dessa combinação pode favorecer o desenvolvimento das plantas. Nesse contexto, o objetivo deste trabalho foi avaliar a aplicação de gel hidrorretentor e doses de nitrogênio (N) sobre os componentes de produção e de produtividade da abobrinha cultivar Caserta.

\section{Material e métodos}

O experimento foi desenvolvido no período de abril a julho de 2012, na área experimental da Universidade Estadual de Mato Grosso do Sul (UEMS) - Unidade Universitária de Aquidauana-MS, com coordenadas geográficas $20^{\circ} 28^{\prime}$ sul, $55^{\circ} 40^{\prime}$ oeste e altitude média de 147 metros. O clima da região, segundo a classificação de Köppen, é do tipo Aw, definido como clima tropical quente subúmido, com precipitação média anual de $1.200 \mathrm{~mm}$, com estação chuvosa no verão e seca no inverno. As temperaturas máximas podem ultrapassar os $40^{\circ} \mathrm{C}$ e ocorrem geralmente nos meses de outubro a fevereiro; já as temperaturas mínimas podem chegar, nos meses mais frios, entre $-3^{\circ} \mathrm{C}$ e $18^{\circ} \mathrm{C}$.

O solo da área experimental é classificado como Argissolo Vermelho-Amarelo distrófico a moderado, de textura arenoargilosa (EMBRAPA, 2006). As características químicas do solo antes da instalação do experimento, segundo metodologia proposta por Sousa \& Lobato (2004), avaliadas na camada de 0 a $0,20 \mathrm{~m}$, foram: $\mathrm{P}$ (resina) $=6,8 \mathrm{mg}$ $\mathrm{dm}^{-3}$; M.O. = 5,2 $\mathrm{g} \mathrm{dm}^{-3} ; \mathrm{pH} \mathrm{CaCl}_{2}=5,5 ; \mathrm{K}, \mathrm{Ca}, \mathrm{Mg}$, $\mathrm{H}+\mathrm{Al}$, e $\mathrm{CTC}=7,0 ; 6,2 ; 2,2 ; 2,1$ e $11,2 \mathrm{mmol}_{\mathrm{c}} \mathrm{dm}^{-3}$, respectivamente.

O delineamento experimental utilizado foi 0 de blocos casualizados, no esquema fatorial $2 \times 5$, com quatro repetições. Foram avaliados o uso do gel hidrorretentor (sem aplicação e com aplicação de $300 \mathrm{~mL}$ de gel hidrorretentor por cova, que corresponderam a $4 \mathrm{~g}$ do produto por L) e cinco 
doses de $\mathrm{N}\left(0 ; 50 ; 100 ; 150\right.$ e $\left.200 \mathrm{~kg} \mathrm{ha}^{-1}\right)$, na forma de ureia $(45 \%$ de $\mathrm{N})$. As dimensões das parcelas experimentais foram constituídas por oito plantas, dispostas no espaçamento de $1,0 \times 1,0 \mathrm{~m}$, sendo utilizadas para as avaliações apenas as quatro plantas centrais. A adubação de manutenção foi realizada antes do plantio sobre área total, utilizando-se de $200 \mathrm{~kg} \mathrm{ha}^{-1}$ da fórmula 04-20-20.

A semeadura da abobrinha 'Caserta' foi realizada diretamente nas covas, em 03 de maio de 2012. Foram utilizadas três sementes por cova. No momento da semeadura, foi depositada a quantia de $300 \mathrm{~mL}$ do gel hidrorretentor e, em seguida, foi colocada uma camada de $8 \mathrm{~cm}$ de solo sobre o gel, onde foi realizada a semeadura a $3 \mathrm{~cm}$ de profundidade. Após a emergência, foi realizado o desbaste, deixando uma planta por cova. As covas utilizadas para o semeio das sementes foram de $20 \times 20 \times 20 \mathrm{~cm}$, compreendendo largura, profundidade e comprimento.

O controle de plantas daninhas foi realizado manualmente, e os demais tratos culturais e fitossanitários foram os normalmente recomendados à cultura da abobrinha. $O$ fornecimento de água foi efetuado com turno de rega de três dias, por meio de sistema de irrigação por aspersão convencional. As doses de $\mathrm{N}$ foram aplicadas, ao redor da cova, em dose única, aos 20 dias após a emergência.

A colheita foi realizada a cada três dias, à medida que os frutos atingiam o comprimento de 18 a $25 \mathrm{~cm}$, com início aos 45 dias após a semeadura, prolongando-se até aos 77 dias após a semeadura.

Foi avaliado o teor de $\mathrm{N}$ na folha através do método de Kjeldahl, coletando-se o limbo foliar de 20 folhas novas, completamente expandidas, no início do florescimento. O material vegetal foi secado em estufa de circulação forçada de ar, com temperatura de $65{ }^{\circ} \mathrm{C}$, por cerca de $72 \mathrm{~h}$. Após a secagem, o material vegetal foi pesado e moído em moinho tipo Wiley equipado com peneira de malhas com abertura de $1 \mathrm{~mm}$ e acondicionado em saquinhos para análises laboratoriais, seguindo-se os métodos descritos por Malavolta et al. (1997).

Para os componentes da produção, foram coletados os frutos das quatro plantas centrais de cada parcela e levados para o laboratório para a determinação do comprimento do fruto, diâmetro apical, médio e basal dos frutos, número de frutos e produtividade comercial por hectare. No campo experimental, foram avaliados a altura das plantas e o diâmetro de caule.

Os dados foram submetidos à análise de variância (teste $\mathrm{F}$ ); e as médias, comparadas pelo teste de Tukey, a 5\% de probabilidade, para aplicação de gel e, para as doses de $\mathrm{N}$ foi realizada a análise de regressão. As análises estatísticas foram processadas, utilizando-se do programa de análise estatística Sanest.

\section{Resultados e discussão}

Não houve efeito significativo da interação entre a utilização do gel hidrorretentor e as doses de $\mathrm{N}$ para nenhum dos parâmetros avaliados. Assim, os resultados foram apresentados separadamente, ou seja, em função das doses de $\mathrm{N}$ e em relação à aplicação ou não do gel hidrorretentor.

$\mathrm{O}$ teor de $\mathrm{N}$ foliar e o comprimento dos frutos não foram influenciados pela aplicação do gel hidrorretentor. Por outro lado, houve efeito do uso do hidrogel na altura e no diâmetro do caule das plantas (Tabela 1).

Tabela 1 - Análise de variância e valores médios do teor de nitrogênio foliar (TNF), altura de plantas (AP), diâmetro de caule (DC) e comprimento de frutos (CF), em função da aplicação de gel hidrorretentor na abobrinha 'Caserta'. Analysis of variance and average values of leaf nitrogen content (TNF), plant height (PH), stalk diameter (DC), and fruit length (FL) depending on the application hidroretentor gel in zucchini 'Caserta'.

\begin{tabular}{|c|c|c|c|c|}
\hline \multirow{2}{*}{ Fator } & TNF & AP & DC & $\mathrm{CF}$ \\
\hline & \multicolumn{4}{|c|}{ Médias } \\
\hline Tratamentos & ------ $\left(\mathrm{g} \mathrm{kg}^{-1}\right)$------ & --------- & ----- $(\mathrm{cm}$ & --------- \\
\hline Sem aplicação de gel & $45,82 \mathrm{a}$ & $101,95 \mathrm{~b}$ & $3,89 \mathrm{~b}$ & $21,59 a$ \\
\hline Com aplicação de gel & $42,68 \mathrm{a}$ & $109,36 \mathrm{a}$ & $4,45 \mathrm{a}$ & $22,10 \mathrm{a}$ \\
\hline Valor de $\mathrm{F}$ & $3,43^{\text {ns }}$ & $0,06^{*}$ & $5,54^{*}$ & $2,04^{\text {ns }}$ \\
\hline CV $(\%)$ & 8,65 & 16,38 & 14,69 & 5,10 \\
\hline
\end{tabular}

กs , * - não significativo e significativo a $5 \%$ de probabilidade, respectivamente, pelo teste $\mathrm{F}$; médias seguidas pela mesma letra, na coluna, não diferem entre si, pelo teste de Tukey, a $5 \%$ de probabilidade. ${ }^{n \text {, }}$, * - not significant and significant at $5 \%$ probability by $F$ test; respectively, means followed by the same letter in the column do not differ by Tukey test at $5 \%$ probability.

Houve maior altura de plantas e diâmetro do caule com a aplicação do gel hidrorretentor (Tabela 1). A obtenção de maiores plantas, com maior diâmetro, quando se fez a aplicação do gel hidrorretentor, pode estar relacionada à capacidade deste polímero em armazenar e disponibilizar água para a planta, conforme comentado por Azevedo et al.
(2002). Diversos trabalhos com diferentes espécies mostram o efeito positivo da aplicação do gel hidrorretentor (Tittonell et al., 2002; Lima et al., 2003; Zonta et al., 2009).

$\mathrm{O}$ teor de $\mathrm{N}$ foliar, a altura de plantas e o comprimento de frutos foram influenciados significativamente pelas doses de $\mathrm{N}$ (Figura 1). $\mathrm{O}$ teor de $\mathrm{N}$ 
foliar e a altura de plantas apresentaram comportamento quadrático e crescente até às doses de $147 \mathrm{e}$ $127 \mathrm{~kg} \mathrm{ha}^{-1}$ de N (Figuras $1 \mathrm{~A}$ e 1B). Diferentemente, o comprimento de frutos ajustou-se ao modelo linear (Figura 1C).
Os teores foliares de $\mathrm{N}$ constatados neste trabalho são superiores aos recomendados por Martinez et al. (1999) para o desenvolvimento adequado da abobrinha (40 $\left.\mathrm{g} \mathrm{kg}^{-1}\right)$.
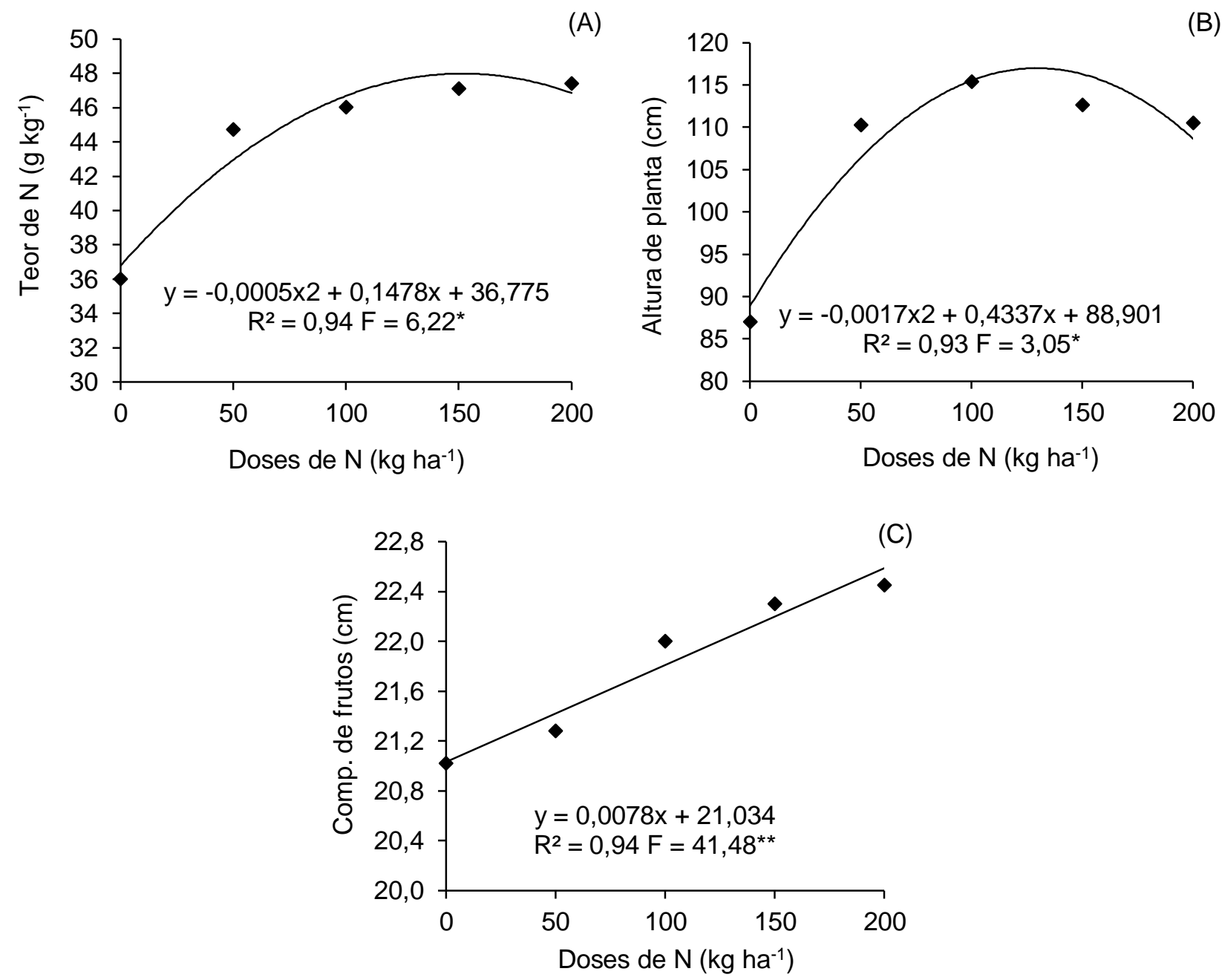

Figura 1 - Teor foliar de N (A); altura de plantas (B) e comprimento de frutos (C) em função das doses de N, na abobrinha 'Caserta'. * ${ }^{* *}$ - significativo a $5 \%$ e $1 \%$ de probabilidade, respectivamente. Leaf nitrogen content $(A)$; plant height $(B)$ and fruit length $(C)$ as a function of nitrogen in the culture of squash Caserta. ${ }^{*},{ }^{* *}$ - Significant at $5 \%$ and $1 \%$ probability, respectively.

Resultados semelhantes foram encontrados por Pôrto et al. (2011), trabalhando com doses de 0 a $400 \mathrm{~kg} \mathrm{ha}^{-1}$ de N na abobrinha 'Caserta', com ajuste quadrático das médias. Por outro lado, a aplicação de doses do composto orgânico, de 0 a $12 \mathrm{t} \mathrm{ha}^{-1}$, associadas às doses do adubo mineral (04-14-08), de 0 a $772 \mathrm{~kg} \mathrm{ha}^{-1}$, na cultura da abóbora híbrida, mostraram que com o aumento das doses de composto orgânico e com a redução das doses do adubo mineral, ocorreu diminuição do teor de N foliar (Silva et al., 1999).

O diâmetro apical, médio e basal dos frutos, o número de frutose e a produtividade comercial por hectare não apresentaram diferenças significativas em relação à aplicação do gel hidrorretentor (Tabela 2).
Mesmo não ocorrendo diferença significativa para o número de frutos e produtividade comercial, os valores com aplicação de gel ficaram 3,08 e $8,6 \%$, respectivamente, superiores ao sem aplicação de gel.

Por outro lado, houve efeito significativo das doses de $\mathrm{N}$ sobre o número de frutos e a produtividade comercial por hectare (Figura 2). Estes parâmetros apresentaram comportamento linear e crescente em função das doses de $\mathrm{N}$ (Figuras 2A e 2B). Isso demonstra a importância de se realizar a aplicação de nitrogênio na cultura da abóbora. Mesmo com doses crescentes, a cultura apresentou produtividade satisfatória. 
Tabela 2 - Análise de variância e valores médios do diâmetro apical (DAF), médio (DMF) e basal do fruto (DBF), número de frutos por hectare (NF) e produtividade comercial (PROD) em função da aplicação do gel hidrorretentor na abobrinha 'Caserta'. Analysis of variance and mean values of the apical diameter (DAF), middle (DMF) and basal fruit (DBF), fruit number (NF), and commercial productivity (PROD) by applying the gel to the hidroretentor zucchini 'Caserta'.

\begin{tabular}{|c|c|c|c|c|c|}
\hline Fator & $\mathrm{DAF}^{\mathrm{ns}}$ & $\mathrm{DMF}^{\mathrm{ns}}$ & $\mathrm{DBF}^{\mathrm{ns}}$ & NF ${ }^{n s}$ & PROD ${ }^{\text {ns }}$ \\
\hline & \multicolumn{5}{|c|}{ Médias } \\
\hline Tratamentos & \multicolumn{3}{|c|}{ - - } & $\mathrm{n}^{0} \mathrm{ha}^{-1}$ & $\mathrm{~kg} \mathrm{ha}^{-1}$ \\
\hline Sem aplicação de gel & $4,43 \mathrm{a}$ & $5,99 \mathrm{a}$ & $6,34 \mathrm{a}$ & $100500 \mathrm{a}$ & $29884 \mathrm{a}$ \\
\hline Com aplicação de gel & $4,55 \mathrm{a}$ & 6,09 a & $6,41 \mathrm{a}$ & $97500 \mathrm{a}$ & 32454 a \\
\hline Valor de F & $0,93^{\text {ns }}$ & $0,56^{*}$ & $0,15^{*}$ & $0,34^{\text {ns }}$ & $2,78^{\text {ns }}$ \\
\hline CV (\%) & 8,75 & 6,97 & 8,35 & 17,15 & 18,06 \\
\hline
\end{tabular}

ns - não significativo a $5 \%$ de probabilidade, pelo teste F; médias seguidas pela mesma letra, na coluna, não diferem entre si, pelo teste de Tukey, a de $5 \%$ de probabilidade. ${ }^{n s}$ - no significant at $5 \%$ probability $F$ test; Means followed by the same letter in the column do not differ by Tukey test at $5 \%$ probability.
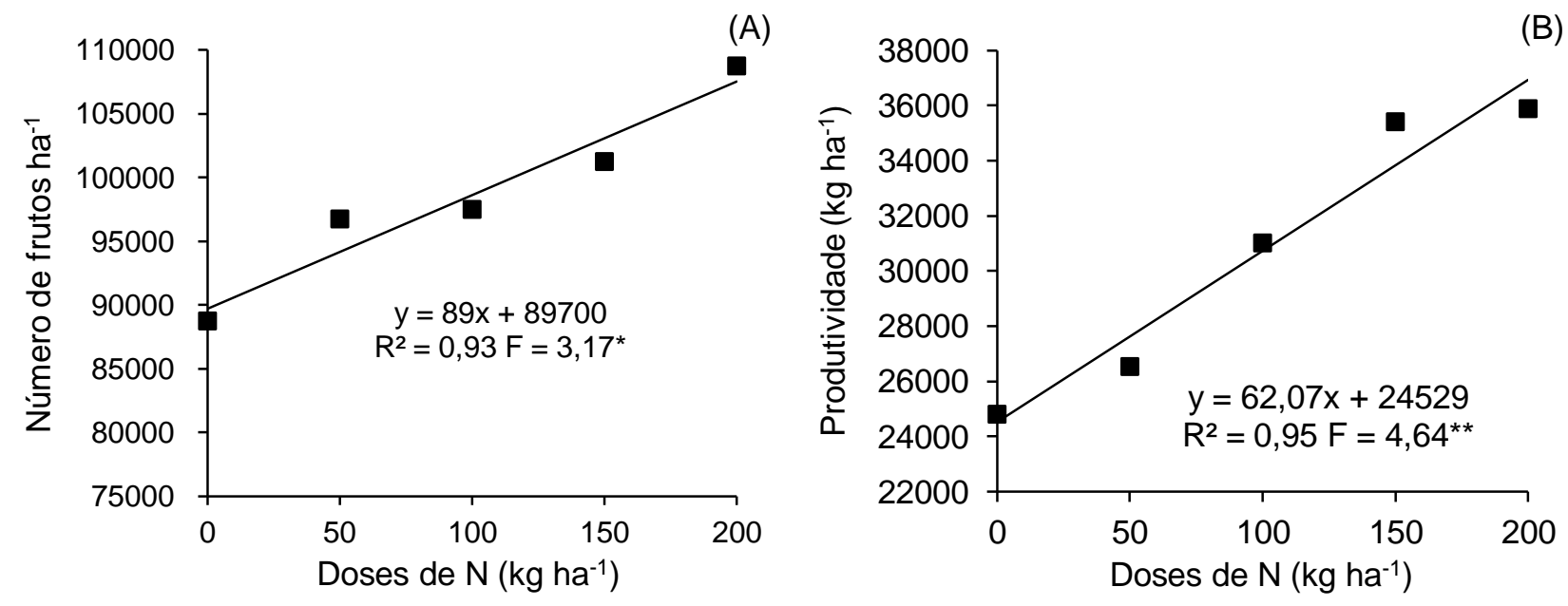

Figura 2 - Número de frutos (A) e produtividade comercial (B) por hectare em função das doses de nitrogênio, na abobrinha 'Caserta'. * ${ }^{* *}$ - Significativo a $5 \%$ e $1 \%$ de probabilidade, respectivamente. Number of fruits per hectare $(A)$ and productivity $(B)$ as a function of nitrogen in the culture of squash Caserta. *, ${ }^{*}$ - Significant at $5 \%$ and $1 \%$ probability, respectively.

Esses resultados são semelhantes aos encontrados por Silva et al. (2011), os quais constataram aumento crescente no número de frutos e na produtividade das abobrinhas 'Menina Brasileira' e Piramoita', quando avaliaram doses de $\mathrm{N}$ entre 0 a $90 \mathrm{~kg} \mathrm{ha}^{-1}$. Os autores ainda acrescentam sobre a necessidade de realizar mais estudos com o intuito de encontrar a dose ideal para alcançar a máxima produtividade. Assim também, Pôrto et al. (2012) verificaram incremento no número de frutos por planta e na produtividade da abobrinha 'Caserta', até 322 e $331 \mathrm{~kg} \mathrm{ha}^{-1}$ de N, respectivamente.

\section{Conclusões}

A aplicação do gel hidrorretentor não influencia na produção da abobrinha cultivar Caserta.

As doses de nitrogênio incrementam linearmente os componentes de produção, tanto para o número de frutos quanto para a produtividade.

\section{Referências}

Albuquerque Filho JAC, Lima VLA, Menezes D, Azevedo CAV, Dantas Neto J, Silva Junior JG (2009) Características vegetativas do coentro submetido a doses do polímero hidroabsorvente e lâminas de irrigação. Revista Brasileira de Engenharia Agrícola e Ambiental, 13(6):671-679. doi: 10.1590/S141543662009000600002

Amaro GB, Vidal MC, Souza RB, Resende FV (2007) Substrato para produção de mudas: aprenda como se faz. Brasília, DF: Embrapa Hortaliças, 8p.

Azevedo TLF, Bertonha A, Gonçalves ACA (2002) Uso de hidrogel na agricultura. Revista de Ciências Agro-Ambientais, 1(1):23-31.

Bastos EA, Cardoso MJ, Melo FB, Ribeiro VQ, Andrade Júnior AS (2008) Doses e formas de parcelamento de nitrogênio para a produção de milho sob plantio direto. Revista Ciência Agronômica, 39(2):275-280. 
Carpes RH, Lúcio AD, Storck L, Lopes SJ, Zanardo B, Paludo AL (2008) Ausência de frutos colhidos e suas interferências na variabilidade da fitomassa de frutos de abobrinha italiana cultivada em diferentes sistemas de irrigação. Revista Ceres, 55(6):590-595.

Demartelaere ACF, Dutra I, Alves SSV, Teófilo TMS, Alves SV (2009) Utilização de polímero hidroabsorvente no meloeiro (Cucumis melon L.) sob diferentes lâminas de irrigação. Revista Caatinga, 22(3):5-8.

EMBRAPA - CNPS (2006) Empresa Brasileira de Pesquisa Agropecuária. Centro Nacional de Pesquisa de Solos. Sistema brasileiro de classificação de solos. Rio de Janeiro, 306p.

Filgueira FAR (2012) Novo manual de olericultura: agrotecnologia moderna na produção e comercialização de hortaliça. Viçosa: UFV, 421p.

IBGE - INSTITUTO BRASILEIRO DE GEOGRAFIA E ESTATÍSTICA (2010) Pesquisa de orçamento familiares: 2008-2009. Rio de Janeiro: IBGE, 282p.

Klosowski ES, Lunardi DMC, Sandanielos A (1999) Determinação do consumo de água e do coeficiente da abóbora na região de Botucatu - SP. Revista Brasileira de Engenharia Agrícola e Ambiental, 3(3):409-412.

Lima LML, Teodoro REG, Fernandes DL, Carvalho HP, Mendonça FC, Carvalho JOM (2003) Produção de mudas de café sob diferentes lâminas de irrigação e doses de um polímero hidroabsorvente. Bioscience Journal, 19(3):27-30.

Malavolta E, Vitti GC, Oliveira AS (1997) Avaliação do estado nutricional das plantas: princípios e aplicações. 2 ed. Piracicaba: Potafos, 1997.

Marques PAA, Bastos RO (2010) Use of different doses of hidrogel for sweet pepper seedling production. Pesquisa Aplicada \& Agrotecnologia, 3(2):59-64.

Martinez HEP, Carvalho JG, Souza RB (1999) Diagnose Foliar. In: Ribeiro AC, Guimarães PTG, Alvarez VVH. (eds.) Recomendações para o uso de corretivos e fertilizantes em Minas Gerais. 5a Aproximação. Viçosa: UFV, p. 143-168.

Oliveira RA, Rezende LS, Martinez MA, Miranda GV (2004) Influência de um polímero hidroabsorvente sobre e a retenção de água no solo. Revista Brasileira de Engenharia Agrícola e Ambiental, 8(1):160163. doi: 10.1590/S1415-43662004000100023.
Pôrto ML, Puiatti M, Fontes PCR, Cecon PR, Alves JC, Arruda JA (2012) Produtividade e acúmulo de nitrato nos frutos de abobrinha em função da adubação nitrogenada. Bragantia, 71(2):190-195.

Pôrto L, Puiatti M, Fontes PCR, Cecon PR, Alves JC, Arruda JA (2011) Índice SPAD para o diagnóstico do estado de nitrogênio na cultura da abobrinha. Horticultura Brasileira, 29(3):311-315. doi: 10.1590/S0102-05362011000300009

Silva LV, Oliveira GQ, Silva MG, Nagel PL, Machado MMV (2011) Doses de nitrogênio em cobertura em duas cultivares de abobrinha no município de Aquidauana-MS. Revista Brasileira de Ciências Agrárias, 6(3):447-451. doi: 10.5039/agraria.v6i3a1127

Silva NF, Fontes PCR, Ferreira FA, Cardoso AA (1999) Adubação mineral e orgânica da abóbora híbrida II. Estado nutricional e produção. Pesquisa Agropecuária Tropical, 29(1):19-28.

Sousa DMG, Lobato E (2004) Calagem e adubação para culturas anuais e semiperenes. In: Sousa DMG, Lobato E (Eds.). Cerrado, correção do solo e adubação. 2.ed. Brasília: Embrapa, p. 283-315.

Tittonell PA, De Grazia J, Chiesa A (2002) Adición de polímeros superabsorbentes en el medio de crecimiento para la producción de plantines de pimiento. Horticultura Brasileira, 20(4):641-645. doi: $10.1590 /$ S0102-05362002000400026

Vale GFR, Carvalho SP, Paiva LC (2006) Avaliação da eficiência de polímeros hidroretentores no desenvolvimento de cafeeiro em pós-plantio. Coffee Science, 1(1)7-13.

Zonta JH, Braun H, Reis EF, Paulucio D, Zonta JB (2009) Influência de diferentes turnos de rega e doses de hidroabsorvente no desenvolvimento inicial da cultura do café conillon (Coffea canephora Pierre). Idesia, 27(3):29-34. doi: 10.4067/S071834292009000300005 . 